\title{
O patrimônio naval e o seu estudo pela Arqueologia: algumas considerações
}

\author{
Ticiano Alves ${ }^{1,2}$
}

(1) Instituto Federal de Educação, Ciência e Tecnologia da Paraíba - Campus Cabedelo, Rua Santa Rita de Cássia 1900, Jardim Camboinha 58310-000, Cabedelo, Paraíba, Brasil. E-mail: ticiano.alves@ifpb.edu.br

(2) Universidade de Coimbra - Palácio Sub-Ripas, Faculdade de Letras, Instituto de Arqueologia, Programa de Pós-Graduação em Arqueologia, Rua de Sub-Ripas, Coimbra 3000-395, Portugal.

Alves T. (2020) O patrimônio naval e o seu estudo pela Arqueologia: algumas considerações. Pesquisa e Ensino em Ciências Exatas e da Natureza, 4: e1586. http://dx.doi.org/10.29215/pecen.v4i0.1586

Editor acadêmico: Carlos Celestino Rios e Souza. Recebido: 25 outubro 2020. Aceito: 01 dezembro 2020. Publicado: 15 dezembro 2020.

Resumo: Nascida do desejo do ser humano de buscar novos horizontes, estreitar relações comerciais e expandir territórios, a arte e a ciência de se deslocar sobre as águas se fez presente na história de pequenas e grandes civilizações às margens de corpos d'água. Atreladas à navegação estão uma série de elementos únicos, endêmicos desse ambiente de chão inconstante, dando origem, em terra e na água, a um amplo e diversificado patrimônio, o naval. Este artigo objetiva apresentar as principais características do patrimônio naval e trazer algumas considerações sobre o estudo desse patrimônio pela Arqueologia.

Palavras chave: Cultura material, comunidade naval, pesquisa arqueológica, Arqueologia Subaquática.

\section{Naval heritage and its study by Archaeology: some considerations}

Abstract: Born from the desire of the human being to seek new horizons, establish commercial relationships and expand territories, the art and science of moving on water was present in the history of small and large civilizations on the margins of water bodies. Linked to navigation are a series of unique elements, endemic to this unstable ground environment, giving rise, on land and in water, to a wide and diversified heritage, the naval. This article aims to present the main characteristics of naval heritage and bring some considerations about the study of this heritage by archeology.

Key words: Material culture, naval community, archaeological research, Underwater Archeology.

\section{Introdução}

Durante milênios os corpos d'água foram utilizados basicamente para dois fins antagônicos: separar e unir. O mesmo mar que divide geograficamente dois continentes, permite sobre suas águas o transporte de mercadorias, como forma de união, e a guerra, como forma de separação. A essa capacidade do ser humano de se deslocar sobre as águas utilizando-se de algum artefato flutuante, dá-se o nome de navegar. Em torno do ato de navegar criou-se conjuntos de elementos únicos, que vão da construção e arquitetura naval, passando pelo manuseio de instrumentos, divisão das funções de trabalho, cultura material que reflete o estilo de vida especializado, edificações em terra e no mar com vistas a orientação e suporte, às formas de se comunicar a bordo, os mitos e os atos religiosos.

Todos esses elementos supracitados compõem o complexo patrimônio naval, cuja designação é originária do latim navalis, que assim como navigabilis (navegável), navifragus (que provoca naufrágio), naviculator (armador da embarcação) e navigator (navegador), 
derivam da palavra navio, do latim navis (barco, embarcação, nau) (Saraiva 2006: 770). Portanto, naval quer dizer aquilo que é próprio "de navio", como se pode constatar no emprego da palavra no latim, como navalis disciplina (ciência marítima), pugna navales (combate naval) e navales socii (marinheiros) (Saraiva 2006).

O presente trabalho aborda as principais características desse patrimônio, perfazendo um caminho que vai da sua distribuição e cultura material, passando pela importância da Revolução Industrial - responsável por profundas transformações de seus elementos em terra e em mar, e fechando com algumas considerações sobre esse estudo patrimonial pela Arqueologia.

\section{A ampla distribuição temporal e espacial}

Uma das particularidades do patrimônio naval é a sua ampla distribuição temporal, que teve um início, mas que não se limita a algum evento que o finalize, diferentemente de diversas outras categorias de patrimônio, que vinculados a períodos da história, como o clássico, que apesar de muitos de seus valores terem perdurado e renascido durante um período muito posterior ao seu dito "final", teve início e fim. O naval teve apenas um início, nascendo com o desejo do ser humano de "expandir horizontes", de buscar conhecer novos lugares, estabelecer comércios, permitir a comunicação com outros povos, alcançar novos pontos de pesca etc.

Desta maneira o patrimônio naval aborda os conjuntos de vestígios que testemunham uma tecnologia em torno da capacidade do ser humano se deslocar sobre as águas. A partir dessa tecnologia, ao longo dos séculos, estruturas em mar (faróis, boias...) e em terra (portos, estaleiros...) foram criadas e desenvolvidas para servirem de apoio à navegação (Clark 2005).

Nos naufrágios que jazem junto aos bentos dos corpos d'água estão os reflexos da evolução tecnológica. Nos portos soterrados pelo tempo estão os indícios de longos períodos de transações comerciais. Nos restos "mortais" de fortalezas localizadas nas entradas de barras, vestígios de batalhas navais estão sob o solo. Percebe-se aqui a plena diversidade e a ampla distribuição espacial do patrimônio naval, que não se restringe apenas aos ambientes submersos, mas que se encontra, também, largamente distribuído em terra.

A exemplo disso, em 2004, durante as obras de construção de um sistema de transporte urbano em Yenikapi / Istambul, Turquia, foi descoberto um porto bizantino do século VI, onde "muitos especialistas estão chamando de o maior sítio arqueológico náutico já descoberto: uma grande escavação que abrange mais de 58.000 metros quadrados" (Covington 2009: 10). Dos 32 naufrágios encontrados até o momento da publicação do artigo, 17 foram escavados, e alguns estão com até $40 \%$ de sua estrutura principal preservada. Segundo a arqueóloga náutica Sheila Matthews, em depoimento recolhido por Richard Covington (2009: 10), os estudos dessas embarcações escavadas irão "revolucionar o nosso conhecimento de construção de navios durante o período Bizantino". Para as escavações em Istambul foram utilizados 800 profissionais entre arqueólogos, engenheiros e operários.

Em se retrocedendo até o século XX, mais precisamente no dia 15 de março de 1942, o vapor britânico SS Dago foi afundado, após um ataque realizado por um avião alemão Fockewulf 200 Condor (Russo 2014: 146-147). Após 63 anos do infortúnio, em 2005, uma equipe de mergulhadores técnicos foi até o local, onde a população de Peniche / Portugal apontava como sendo os restos do navio "Dago". Contudo, havia dois conjuntos de vestígios que distavam apenas 500 metros entre eles. Para descobrir qual deles era o Dago, procedeu-se o registro imagético dos cascos soçobrados, "à identificação de estruturas distintivas nos destroços que pudessem ser comparadas com os planos de construção e com o registro original do navio no porto de Hull" (Russo 2012). Por meio da comparação dos dados coletados com informações contidas na documentação sobre o navio, foi possível identificar o SS Dago, cujo porão guarda carga sobrevivente, que vão de frascos farmacêuticos a rolos de linóleo. O outro soçobro permanece incógnito. 


\section{O naufrágio como um achado fechado}

O termo "achado fechado" designa um conjunto de objetos, que num dado momento, "foram concebidos como formando uma entidade coerente: o mobiliário do morto, o aparelho cerimonial, os objetos de valor" (Moberg 1981: 50). A partir dessa definição é possível encontrar muitas afinidades desse tipo de achado com uma embarcação naufragada. Dependendo da forma como aconteceu o naufrágio, que resultará por si na integridade ou não dos elementos que estão contidos em seu interior, o mesmo pode ser considerado um achado fechado, uma vez que esses elementos fazem parte de uma "entidade coerente" ou "homogênea".

O navio sueco Vasa, naufragado em Estocolmo, em 10 de agosto de 1628, é um dos maiores exemplos de que um naufrágio pode ser um achado fechado. No dia 24 de abril de 1961, 333 anos depois, o Vasa foi resgatado das águas geladas por meio de uma operação que custou anos de planejamento e preparação. Junto com o seu casco original (95\% preservado) submergiu inúmeros elementos contidos neste invólucro, "entre eles, encontram-se esqueletos dos membros da tripulação, bem como os seus pertences e o equipamento do navio" (Vasa Museet 2016). Todos esses elementos pertencem ao mesmo conjunto e foram "depositados" em um único instante, daí defini-lo como um achado fechado.

No site oficial do Vasa Museet, esse navio é comparado a uma máquina do tempo, que no ato do seu afundamento, "o tempo parece ter parado". Utilizando-se desse mesmo argumento, o arqueólogo subaquático Gilson Rambelli, em seu artigo "Tráficos e Navios Negreiros: contribuição da arqueologia náutica e subaquática" (Rambelli 2006: 70), faz uma interessante analogia, onde afirma que um naufrágio é um sítio que teve a sua história repentinamente interrompida, por isso, trata-se de uma "cápsula do tempo". Aquele momento, descontinuado de forma tão abrupta, está "congelado", carregando os "restos materiais (...), testemunhos" de uma época.

\section{A cultura material naval}

From hairpins to computers and cars, we surround ourselves with artefacts. What distinguishes humans from other animals is not that we make and use tools. Rather, it is our total reliance on these objects, for our lives are shaped by, and in return shape, technologies (Hollenback \& Schiffer 2010: 313).

De garrafas a sextantes e agulhas magnéticas, o marinheiro está cercado por artefatos. Há uma grande riqueza de artefatos pertencentes ao meio aquaviário confeccionados especificamente para contribuir com o ato de navegar ou com a complexa e, muitas vezes, quase inóspita, vida a bordo. Vale salientar que essa cultura material naval não se encontra restrita apenas às embarcações, mas também pode ser achada nas infraestruturas de apoio naval, como: portos, faróis, cais, trapiches, entre outras.

A ausência dos atores sociais (Lima 2011: 12) - os tripulantes, passageiros, trabalhadores portuários - torna a cultura material naval a fonte primária para a obtenção de informações concernentes ao passado das navegações. Os "seus usos, as suas apropriações sociais, as técnicas envolvidas na sua manipulação, a sua importância econômica e a sua necessidade social e cultural" (Barros 2009: 5) são dados a serem obtidos através do estudo desses artefatos.

$\mathrm{Na}$ cultura material descoberta, particularmente, nas escavações em embarcações naufragadas, é comum se deparar com uma peculiaridade sobre a sua origem, que está no fato de que nem todos os artefatos escavados são endêmicos dessas embarcações. Isso pode ocorrer por uma infinidade de fatores, contudo, destaca-se aqui, apenas três: os artefatos integravam a carga da embarcação; se tratava de objetos domésticos e pessoais (Bettencourt \& Carvalho 2011); ou eram extrínsecos ao sítio, possuindo "cronologias diversas" e estando "fora do contexto original" (Bettencourt et al. 2003: 6).

Não era incomum que no século XIX as embarcações de carga transportassem para o continente americano grande variedade de itens produzidos na Europa. Como aconteceu com o navio Adele, que vindo da França com destino a Paraíba, desembarcou em maio de 1869: 
candeeiros a gás, lamparinas, chaminés, pratos de porcelana, xícaras e diversas outras peças de porcelanato (O Publicador 1869: 2). Os objetos domésticos e pessoais poderiam pertencer a um membro da tripulação, a um passageiro ou até compor parte da carga, como ocorreu com o navio Adele. Nesse mesmo período, a maior parte dos passageiros desses navios eram imigrantes que traziam consigo o pouco dos bens de uso pessoal que podiam (Alves 2016).

No que concerne os artefatos extrínsecos as complicações são maiores (Freire et al. 2012), uma vez que eles foram inseridos "acidentalmente" no sítio arqueológico por um agente externo, podendo esta localidade, por exemplo, ser uma região "depositária dos sedimentos (...) [provenientes de] dragagens" (Bettencourt et al. 2003: 14).

$\mathrm{O}$ fato de o objeto não ser endêmico àquela determinada embarcação, não retira dele $o$ seu valor, mas apenas lhe acrescenta um status de que ele pertence a um ambiente distinto daquele onde se encontra.

\section{As acumulações e os achados isolados}

Diferentemente dos achados fechados, as acumulações são provenientes de um processo de "sedimentação" onde os elementos foram sucessivamente depositados. Trata-se de formações acidentais, ocasionadas a partir de naufrágios, "objetos perdidos, deitados fora ou abandonados" (Moberg 1981: 51). Essas formações são também chamadas de sítios depositários "por não estarem inseridas diretamente em um contexto arqueológico conhecido da região ou por não estarem localizados em camadas de solo cuja datação seja possível (Rambelli 2002: 50).

Enquanto nos achados fechados todos os elementos foram simultaneamente depositados, pertencendo a uma mesma data de depósito, apesar de seus artefatos serem de datas e origens distintas de fabricação, nas acumulações o processo de identificação da origem se faz de maneira bem mais intrincada, tendo que considerar as correntes, o relevo batimétrico, o tipo de solo, as variações anuais de marés etc.

Em se exemplificando, na retomada do Projeto de São Julião da Barra / Portugal foi realizada uma campanha de escavação entre outubro de 1996 e outubro de 1997. Nesse processo foram contempladas duas zonas, sendo a primeira os restos de um casco de madeira e a segunda, com $100 \mathrm{~m}^{2}$, uma "depressão natural do fundo rochoso que permitiu a acumulação de material arqueológico" (Freire et al. 2012: 349). Avaliar os processos de formação da acumulação e correlacionar as culturas materiais ali existentes, com vários momentos da história, trata-se de um difícil objetivo, como relatado por Freire e colaboradores:

\footnotetext{
Este objectivo é ainda mais difícil de atingir em contextos costeiros de baixa profundidade, com alta energia, marcados por dinâmicas sedimentares e pela deslocação horizontal e vertical dos materiais mais leves, com baixa densidade. De facto, os materiais tendem a entrar no registo geológico, comportando-se como os sedimentos até atingir estratos estáveis, no limite de acção da ondulação, ou a se acumularem em zonas do fundo com características muito específicas (como as fissuras entre afloramentos ou junto à base dos obstáculos) (Freire et al. 2012: 352)
}

Já os achados isolados não são incomuns nas prospecções subaquáticas. Muitos deles provêm, para além dos casos supracitados, de peças que se soltam de embarcações durante a navegação em mau tempo, por exemplo, ou são alijadas por motivos diversos. Uma âncora, um canhão, um sino, uma carga que solta do convés, todos esses objetos têm uma história e uma origem. Em muitos casos não será encontrado o navio a quem pertencia, mas poderá, por exemplo, tomar conhecimento do nome do fabricante, ano de fabricação e país de origem, como ocorreu com dois dos três sinos encontrados no baixio de Lucena / PB em 1994, onde foi possível identificar que o fundidor era o holandês Henrick Wegeaert (Figuras 1-2; Alves 2019: 87, 90). Contudo, a região onde foram encontrados podem guardar mais vestígios do mesmo navio ou até o casco dele, sendo de ótima praxe a realização de um processo de investigação mais minucioso no seu entorno. 
A exemplo, em 2001 e 2002, foram achadas no rio Arade, Portugal, três ânforas e dois fragmentos do tipo Dressel 7-11, que não distavam 50 metros entre si, permitindo levantar a hipótese de que se tratava de vestígios de um naufrágio da época romana. Esta hipótese só poderá ser confirmada com "o alargamento das sondagens por escavação em redor do sítio onde foram localizadas as referidas ânforas" (Bettencourt et al. 2003: 12). Como a região onde se encontrou os vestígios passou por dragagens, possivelmente esses achados devem ter sido dispersados ou se encontravam em cotas inferiores as apresentadas pelo fundo atual.

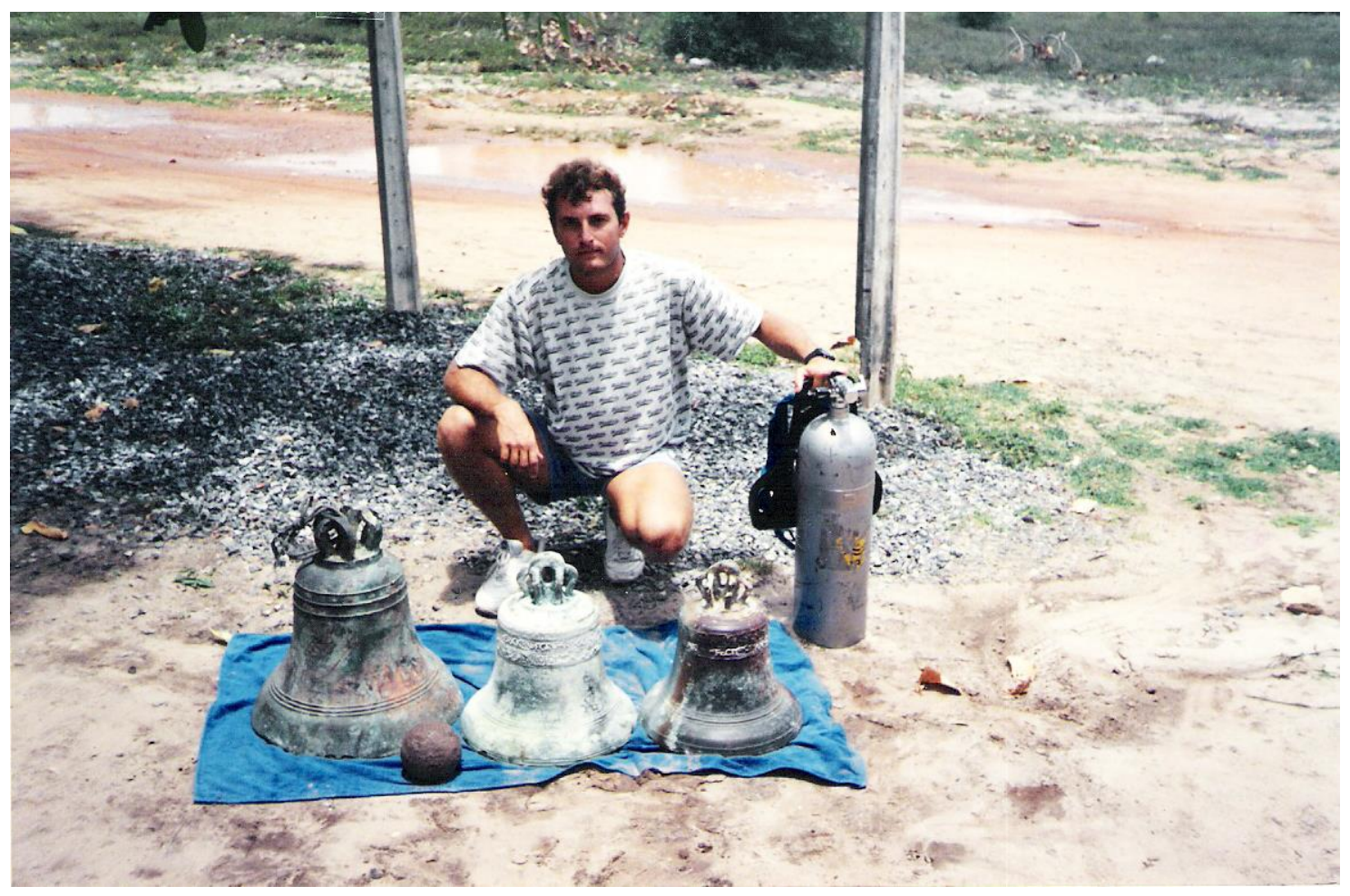

Figura 1. Sinos encontrados pelo Sr. Gustavo Adelino de Lima no baixio de Lucena, Paraíba, em 1994 (Alves 2019: 87).

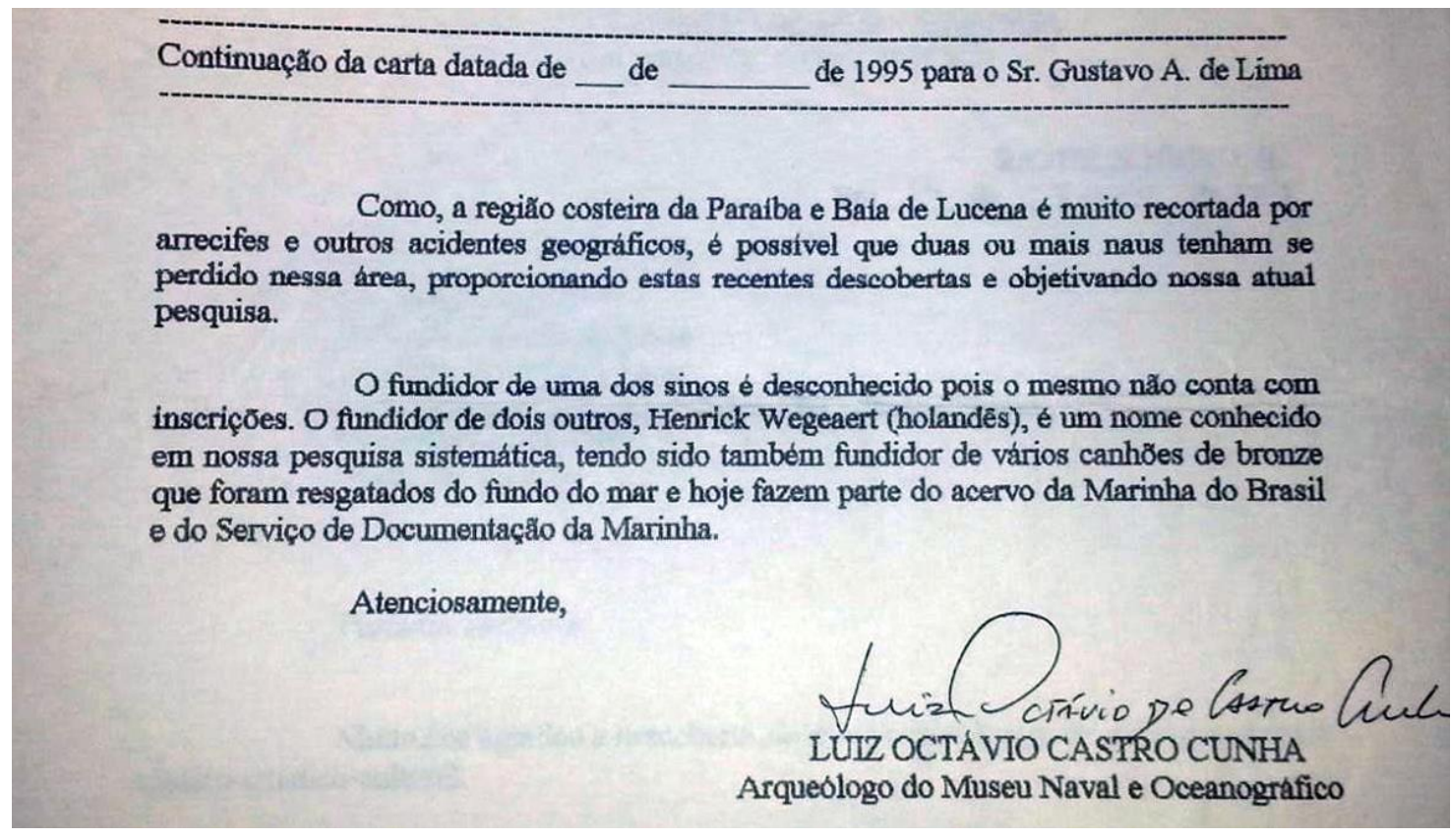

Figura 2. Segunda página da carta redigida pelo Arqueólogo do Museu Naval e Oceanográfico, Luiz Octávio Castro Cunha, endereçada ao Sr. Gustavo Adelino de Lima, sobre a pesquisa realizada com os sinos doados à Marinha do Brasil (Alves 2019: 90). 
Tanto as acumulações, como os achados isolados possuem amostras, que testemunham a passagem humana naquela localidade e se coloca "perante um reduzido número de acontecimentos que emerge do todo que permanecerá desconhecido" (Moberg 1981: 52). Para Rambelli (2002: 51), mesmo se encontrando fora de contexto arqueológico, "a identificação e o estudo desses testemunhos [...] permitem a constatação de informações importantes para o histórico da navegação”.

\section{O novo patrimônio naval}

A Revolução Industrial provocou profundas transformações no comércio do século XIX. As novas relações mercantis, as mudanças da natureza de suas trocas e a intensificação da movimentação de mercadorias (matérias-primas e produtos manufaturados) eram constantemente alimentadas pelo crescimento das atividades industriais (Monié \& Vasconcelos 2012).

As inovações tecnológicas chegaram ao transporte aquaviário quebrando o domínio milenar dos ventos, como forma de propulsão, e da madeira, como principal material construtivo (Natal 1991). As fábricas exigiam que seus produtos fossem escoados de forma segura e em tempo cada vez menor e que as suas matérias-primas, extraídas/produzidas, em sua maioria, em outros continentes, nos ditos países periféricos, estivessem à disposição (Monié \& Vidal 2006). Não cabiam mais as longas e irregulares viagens comerciais e as incertezas da proteção das cargas. Assim, com as inovações, as embarcações, agora de aço e movidas à vapor, vieram suprir essas demandas, transportando em menor tempo e "de forma segura volumes crescentes de mercadorias em longas distâncias” (Monié \& Vasconcelos 2012).

"Paralelamente, os portos das cidades inseridas no mundo industrial moderno foram reestruturados para acompanhar o movimento de modernização do transporte marítimo" (Monié \& Vidal 2006: 979). A introdução de equipamentos para a otimização do embarque e desembarque de cargas, o aumento da profundidade para receber embarcações de maior calado e a criação de estruturas de armazenamento destinadas a cargas específicas são apenas algumas das transformações incutidas "pelo aumento regular das trocas marítimas e pela gestão descontínua dos fluxos de mercadorias” (Chaline 1994: 25 apud Monié \& Vasconcelos 2012).

Os efeitos da industrialização se instalaram não apenas nos portos, mas nas cidades portuárias. Chaline (1994), em sua obra “Ces ports qui créèrent des villes”, propõe a divisão, em quatro fases, do desenvolvimento do "par” cidade/porto, em relação ao avanço da tecnologia (Chaline 1994: 34 apud Henry 2006: 11), sendo elas:

- $\quad 1^{\text {a }}$ Fase - Pré-industrial (antes do século XIX), quando os navios ainda são de madeira e à vela, a cidade e o porto estão entrelaçados com baixa especialização funcional do território;

- $\quad 2^{\mathrm{a}}$ Fase - Industrial (século XIX à início do século XX), os navios são de metal e à vapor, o surgimento das ferrovias, e a cidade está justaposta com o porto, com uma área portuária fortemente especializada, havendo uma ruptura entre a cidade e a água;

- $3^{\mathrm{a}}$ Fase - Pós-industrial “A” (1970-1980), os navios foram consideravelmente aumentados (gigantismo), o combustível é derivado do petróleo e transporte rodoviário em foco, há a suburbanização da população e de certas atividades portuárias, desurbanização, formação de terreno baldio...;

- $\quad 4^{a}$ Fase - Pós-industrial “B” (1990-2000), a economia da informação e da comunicação, experiências (esboços) de reurbanização de áreas da orla marítima.

Na Fase Industrial ( $2^{\mathrm{a}}$ Fase) houve o nascimento de um novo modal de transporte: o ferroviário (Natal 1991: 296). Este fazia de forma rápida, eficiente e com menor custo a ligação entre as áreas industriais, os portos e as áreas produtoras de matérias-primas (Borges 2011: 27). Tomando como exemplo o Brasil oitocentista, havia uma interligação do porto do Rio de Janeiro, então capital do império brasileiro, com as “[...] regiões potencialmente produtoras de 
bens primários que se integravam à economia agro-exportadora” (Borges 2011: 30). Neste século, os caminhos de ferro "simbolizavam o progresso material das nações" (Borges 2011: 28), o que desencadeou um "boom ferroviário", sendo o "[...] inglês no segundo quartel do século XIX, o norte-americano após a Guerra Civil e o alemão no último quartel do século XIX” (Goularti Filho 2007: 459).

Todas essas transformações criaram um "Novo Patrimônio Naval" que, por sua vez, pelas suas novas características, também foi inserido em uma nova vertente, intitulada: Patrimônio Industrial. De acordo com a Carta de Nizhny Tagil Ticcih, esta nova vertente do patrimônio:

[...] compreende os vestígios da cultura industrial que possuem valor histórico, tecnológico, social, arquitectónico ou científico. Estes vestígios englobam edifícios e maquinaria, oficinas, fábricas, minas e locais de processamento e de refinação, entrepostos e armazéns, centros de produção, transmissão e utilização de energia, meios de transporte e todas as suas estruturas e infra-estruturas, assim como os locais onde se desenvolveram actividades sociais relacionadas com a indústria, tais como habitações, locais de culto ou de educação (Ticcih 2003: 3).

Os amplos galpões em metal, os cais e faróis em concreto armado, as dragas à vapor, os navios em aço, os grandes estaleiros de construção de vapores, as interligações entre os modais de transporte marítimo e ferroviário e as gruas elétricas são apenas alguns dos elementos que compõem o "Novo Patrimônio Naval", que pode também ser chamado de Patrimônio Naval Industrial.

\section{A comunidade naval}

O patrimônio naval possui uma grande complexidade que excede os vestígios (sítios arqueológicos e cultura material) originários do ato de navegar e de todas as suas decorrências construção naval, o estabelecimento dos portos, cais, píeres, faróis, pesca, entre outras. Para compreender o porquê dessa complexidade, se fará uma comparação das embarcações com um habitat, que no sentido arqueológico, pode ser definido como "qualquer formação de vestígios que atesta uma estadia sem duração bem definida" (Moberg 1981: 51). Assim como em um habitat, uma embarcação é composta por diversos "habitantes" que exercem funções distintas com objetivos holísticos comuns (sobrevivência, comércio, batalha, entre outros); existe uma hierarquia bem definida; a linguagem é endêmica; a moradia é temporária, com pouco conforto e possuindo uma arquitetura variável; há atos religiosos e misticismos; possui uma cultura material própria e adaptada ao meio; por fim, trata-se de uma comunidade. Mas por que uma comunidade? O que colocaria esse conjunto de trabalhadores marítimos como uma comunidade? Comunidade é definida por Moberg (1981: 168) como uma sociedade de reduzidas dimensões (microssocial) e "limitada a um lugar restrito" (microespacial). Uma embarcação se encaixa nessa descrição, pois trata-se de uma localidade limitada pela própria arquitetura naval onde seus "habitantes" são de reduzido número.

Em se fazendo um breve parênteses sobre a linguagem falada pela comunidade naval, a sua endemia a bordo não é oriunda da região de onde provêm os integrantes de uma embarcação, mas na peculiaridade com que os próprios marinheiros têm de se expressarem de forma distinta ao que se faz em terra. Pode-se considerar a endemia da linguagem a bordo uma variante dialetal, uma geolinguística que ultrapassa a distribuição de terras pela política, e que se alterna pelo mero fator de estar no mar.

Em se entendendo que os trabalhadores marítimos são membros de uma comunidade naval, se propõe a seguir classificar essa microssociedade em categorias vinculadas ao seu trabalho, uma vez que existem diferenças significativas entre elas.

- Mercante - trata-se de uma comunidade cuja vida se dá a bordo ligada ao comércio de longo curso e cabotagem. 
- Militar - comunidade cujos elementos são membros de uma embarcação destinada à defesa e ao combate.

- Pesca - os membros dessa comunidade possuem uma organização de trabalho bastante distinta das demais, devido a peculiaridade de sua atividade extrativista.

- Portuária e construção naval - pertencem a uma comunidade de terra responsável pelo suporte das comunidades de vida a bordo.

De certo que muitas dessas categorias se subdividiriam em outras, formando comunidades mais especializadas. $\mathrm{O}$ que todas elas possuem em comum é o fato de estarem ligadas a atividade da navegação e unicamente por esse motivo pertencerem a uma comunidade maior, a naval.

\section{Algumas considerações sobre o estudo do patrimônio naval pela Arqueologia}

A realização de estudos sobre o patrimônio naval requer levar em consideração os trabalhadores do mar como sociedade de características microssocial e microespacial. Sendo assim, procurar-se-á os pedaços dessa sociedade fragmentada, que estão distribuídos ao longo de rios, mares, lagos e em terra e no subsolo, visando reconstruí-la para entender o seu funcionamento. Em outras palavras, o objeto do estudo é o homem do mar e não o naufrágio, o porto, o farol, ou qualquer outro vestígio material sobrevivente da relação humana com o "meio naval".

Através da ampliação da visão sobre essa comunidade, proporcionado pela investigação científica multidisciplinar, em especial, pelas Arqueologia, História e Etnologia, esta última no âmbito "antropologia social" (Moberg 1981: 186), é possível procurar discernir os elementos que a compõem, as relações, as hierarquias. $\mathrm{O}$ emprego das fontes arqueológicas como testemunhos de atividades marítimas ou de relações humanas intra (relação entre os membros de uma mesma embarcação) e extra-embarcações (relações comerciais, militares ou de produção) permitirá responder a esses questionamentos.

Em se sabendo que "os achados [como fontes arqueológicas] são testemunhos de acontecimentos" (Moberg 1981: 52) é primordial conhecer a sua história, que pode ser definida por três momentos distintos: origem (fabrico, construção), atribuição (utilização ou tipo de serviço) e acontecimento final.

O método empregado na construção de embarcações faz parte de um dos momentos dos testemunhos arqueológicos: a origem. Para o arqueólogo naval Patrice Pomey existem três princípios construtivos navais (Pomey et al. 2012): Shell-first, onde o tabuado exterior da embarcação é autossustentável, ficando como a estrutura primária; Frame-based (ou Skeleton) as balizas são pré-determinadas e compõem a estrutura primária onde posteriormente será fixado o tabuado exterior; e o Bottom-based, diz respeito a várias pranchas de fundo unidas e a elevação da estrutura à proa e a popa, obtendo assim a forma.

A escolha de uma determinada localidade para servir de apoio à navegação e para a construção de uma infraestrutura que se adeque as necessidades navais também está vinculada a origem. Quais as razões meteorológicas, técnicas, estratégicas, geográficas, oceanográficas, batimétricas ou topográficas, que levaram a seleção daquela localidade? Tomando como exemplo o fundeadouro em Olisipo (utilizado entre os séculos I a.C. e V d.C.), descoberto durante a construção de um parque de estacionamento na Praça D. Luís I, junto ao Cais de Sodré, em Lisboa, a região fora selecionada pelos romanos por sua posição estratégica favorável.

O porto de Olisipo era um dos mais importantes de toda a fachada Atlântica. por aqui passava uma rota marítima que, desde o mediterrâneo, abastecia os exércitos de Roma estacionados na Britânia e Germânia Inferior, actuais regiões da Grã-Bretanha e parte da costa norte da moderna Alemanha (Losada 2015: página). 
A forma como um dado objeto, proveniente de um achado isolado, era empregado a bordo de uma embarcação; ou como transcorria o cotidiano de trabalho de uma fortaleza às margens de um corpo d'água; fazem parte do segundo acontecimento necessário para se conhecer a história de um testemunho: a "utilização ou atribuição".

Um porto abandonado, o naufrágio, o descarte ou perda de um dado artefato fazem parte do terceiro e último momento: o "acontecimento final". Como ilustração desse momento, volta-se para meados do século XVII quando fora construído na Ria Formosa, Algarve / Portugal, o Forte de São Lourenço. Este, cercado de inúmeros intempéries, por ter sido edificado na "ponta de uma elevação de areia" (Claudino 2012: 18), enfrentou dificuldades que tiveram início já na sua concepção, tendo sofrido diversas reconstruções até o ano de 1821, na altura em que perdeu o seu uso militar ("abandono"). Em 2006 ocorreram as primeiras investigações de campo, tendo sido realizadas por uma equipe formada por pesquisadores da Universidade Autónoma de Lisboa e da Universidade de Connecticut. Desde então diversos outros trabalhos ocorreram a fim de discutir "a funcionalidade desta estrutura militar ao longo da Idade Moderna, integrando-a na planificação da defesa marítima da costa algarvia” (Claudino 2012: V).

É fato que, muitas vezes, não é possível conhecer a "natureza do acontecimento último revelado pela descoberta" (Moberg 1981: 53). Contudo, como já se afirmou, todo achado é testemunha de acontecimentos, estando, portanto, nele, a possibilidade do levantamento de hipóteses que poderão resultar em respostas. Frequentemente pode-se fazer necessário recomeçar o percurso arqueológico, fazendo novos questionamentos, voltando para campo para proceder outras observações e descrições, e retomando o trabalho de laboratório com análises, associações, e assim, novas interpretações (experimentação de hipóteses) e respostas.

A cultura material e os sítios arqueológicos originários de atividades navais podem ser estudados diretamente e indiretamente. Diretamente, por meio de museus e coleções e "indiretamente sob todas as formas documentais: verbais, cartográficas, fotográficas, séries de arquivos" (Moberg 1981: 44). Assim ocorreu com o trabalho de investigação de A. J. Parker que publicou em 1992 o catálogo "Ancient Shipwreck of the Mediterranean \& the Roman Provinces", com 1259 naufrágios, cujos dados foram obtidos através da utilização de fontes que partiam de boatos a relatórios de trabalhos arqueológicos.

Neste contexto, espera-se que esse trabalho possa contribuir para levantar novas discussões sobre o estudo do patrimônio naval, e que estas promovam o aprofundamento dos seus conceitos e estabeleça metodologias de investigações de caráter multidisciplinar, essenciais para uma melhor interpretação dos vestígios materiais sobreviventes e compreensão da importância destes para as comunidades associadas aos mesmos.

\section{Agradecimentos}

Agradeço ao Professor Doutor Vasco Mantas (Universidade de Coimbra, Portugal) pela orientação nas investigações e a revisão crítica do manuscrito efetuada por todos os avaliadores anônimos.

\section{Referências}

Alves T. (2016) Mecanismos de formação de rotas marítimas no Atlântico para os séculos XIX e XX. Jornadas do Mar. Escola Naval. Novos Rumos, Novos Desafios. Almada: Base Naval de Lisboa, 10: 212-221.

Alves T. (2019) Navegações Marítimas Mercantes no Extremo Oriental das Américas-1850-1950. Volume 2. Tese (Programa de Pós-Graduação em Arqueologia). Universidade de Coimbra, Faculdade de Letras, Coimbra, Portugal.

Barros J.D'A. (2009) História da Cultura Material: notas sobre um campo histórico em suas relações intradisciplinares e interdisciplinares. Patrimoniuss: 1-17.

Bettencourt J. \& Carvalho P. (2011) A história submersa na baía da Horta: resultados preliminares dos trabalhos arqueológicos no "naufrágio do marfim" (primeiro quartel do 
século XVIII). O Faial e a Periferia Açoriana nos séculos XV a XIX. Actas do V Colóquio: 139152.

Bettencourt J., Carvalho P. \& Caleja P. (2003) Relatórios dos trabalhos efectuados em 2002 nos sítios de Arade B2 e C no âmbito do projecto ProArade. Lisboa: Centro Nacional de Arqueologia Náutica e Subaquática. 78 p.

Borges B.G. (2011) Ferrovia e modernidade. Revista UFG, 13(11): 27-36.

Clark C. (2005) Coming into the light: the rediscovery and reuse of naval heritage buildings. WIT transactions on the built environment, 79: 33-44. https://doi.org/10.2495/MH050041

Claudino M.F. (2012) Forte de São Lourenço (Olhão): Arqueologia e História de uma Fortificação Moderna. Dissertação (Programa de Pós-Graduação em Arqueologia). Universidade Nova de Lisboa, Faculdade de Ciências Sociais e Humanas, Lisboa, Portugal.

Covington R. (2009) Uncovering Yenikapi. Houston: Saudi Aramco World. Volume 60. p. 8-17.

Freire J., Bettencourt J.A., Lopes G., Baptista B. \& Baço J. (2012) Valorização do Património Cultural Subaquático de Cascais - Oeiras. O Complexo arqueológico de São Julião da Barra. Jornadas do Mar. Escola Naval. O reencontro com o mar no século XXI. Almada: Base Naval de Lisboa, 8: 348-352.

Goularti Filho A. (2007) Melhoramentos, reaparelhamentos e modernização dos portos brasileiros: a longa e constante espera. Economia e Sociedade, 16(3): 455-489. https://doi.org/10.1590/S0104-06182007000300007

Henry M. (2006) Villes portuaires en mutation. Dissertação (Programa de Pós-Graduação em Geografia). Université de Lausanne, Lausanne.

Hollenback K.L. \& Schiffer M.B. (2010) Technology and Material Life (p. 313-332). In: Hicks D. \& Beaudry M.C. (Eds). The Oxford Handbook of Material Culture Studies. New York: Oxford University Press. https://doi.org/10.1093/oxfordhb/9780199218714.001.0001

Lima T.A. (2011) Cultura material: a dimensão concreta das relações sociais. Boletim do Museu Paraense Emílio Goeldi - Ciências Humanas, 6(1): 11-23.

Losada R. (2015) Sinopse - Fundeadouro romano em Olisipo. Documentário: Fundeadouro Romano em Olisitpo. Disponível em: https://goo.gl/o0cle8 (Acesso em: 25/03/2015).

Moberg C.A. (1981) Introdução à Arqueologia. Tradução Maria Raquel Henriques da Silva. Lisboa: Edições 70. 227 p.

Monié F. \& Vasconcelos F.N. (2012) Evolução das relações entre cidades e portos: entre lógicas homogeneizantes e dinâmicas de diferenciação. Confins, 2012(15): 1-18. https://doi.org/10.4000/confins.7685

Monié F. \& Vidal S.M.S.C. (2006) Cidades, portos e cidades portuárias na era da integração produtiva. Revista de Administração Pública, 40(6): 975-995. https://doi.org/10.1590/S003476122006000600003

Natal J.L.A. (1991) Transporte, ocupação do espaço e desenvolvimento capitalista no Brasil: história e perspectivas. Ensaios FEE, 12(2): 293-307.

O PUBLICADOR (1869) Attenção. Parahyba do Norte. 5 de maio 1869. 4 folhas, p. 2. Disponível em: http://memoria.bn.br/DocReader/215481/5252 (acesso em: 04/08/2017).

Parker A.J. (1992) Ancient Shipwrecks of the Mediterranean \& the Roman Provinces. BAR International Series 580. Oxford, England: Hadrian Books Lts. 547 p.

Pomey P., Kahanov Y. \& Rieth E. (2012) Transition from Shell to Skeleton in Ancient Mediterranean Ship-Construction: analysis, problems, and future research. The International Journal of Nautical Archaeology, 41(2): 235-314. https://doi.org/10.1111/j.1095-9270.2012.00357.x

Rambelli G. (2002) Arqueologia até debaixo d'água. São Paulo: Maranta. 159 p.

Rambelli G. (2006) Tráfico e navios negreiros: contribuição da Arqueologia Náutica e Subaquática. Revista Navigator, 2(4): 59-72.

Russo J. (2012) A busca do SS Dago. Portugal: National Geographic. p. 141.

Russo J. (2014) O vapor Britânico SS Dago - 1942. Roteiro da exposição "O Tempo Resgatado ao Mar". Lisboa: Museu Nacional de Arqueologia. p. 146-147. 
Saraiva F.R.S. (2006) Novíssimo Dicionário Latino-Português. 12 edição. Rio de Janeiro: Livraria Garnier. 1297 p.

Ticcih - The International Committee for the Conservation of the Industrial Heritage (2013) Carta de Nizhny Tagil sobre o Património Industrial. Jul. 2003. Tradução da responsabilidade da APPI - Associação Portuguesa para o Património Industrial. Disponível em: http://ticcih.org/wp-content/uploads/2013/04/NTagilPortuguese.pdf (Acesso em 12/06/2018).

Vasa Museet (2016) Museo Vasa. Disponível em: http://www.vasamuseet.se/pt (Acesso em 21/06/2016). 